\title{
Enhanced strength and ductility of AZ80 Mg alloys by spray forming
}

\section{and ECAP}

Lingling Tang ${ }^{1}$, Yonghao Zhao ${ }^{1 *}$, R. K. Islamgaliev², Chi Y. A. Tsao ${ }^{3}$, R.Z.

$$
\text { Valiev }^{2,4} \text {, E.J. Lavernia }{ }^{5} \text {, and Y.T. Zhu }{ }^{1,6}
$$

${ }^{1}$ Nano Structural Materials Center, School of Materials Science and Engineering, Nanjing University of Science and Technology, Nanjing 210094, China

${ }^{2}$ Institute of Physics of Advanced Materials, Ufa State Aviation Technical University, 12K. Marx St., Ufa, Russia

${ }^{3}$ Department of Materials Science and Engineering, National Cheng Kung University, 1 Ta Hsue Road, Tainan 701, Taiwan

${ }^{4}$ Laboratory for Mechanics of Bulk Nanomaterials, Saint Petersburg State University, 28 Universitetsky prospekt, Peterhof, Saint Petersburg, 198504, Russia

${ }^{5}$ Department of Chemical Engineering and Materials Science, University of California, Irvine, CA 92697, USA

${ }^{6}$ Department of Materials Science \& Engineering, North Carolina State University, Raleigh, NC 27695-7919, USA

\begin{abstract}
The relatively low strength and poor ductility of conventional AZ80 Mg alloys have been attributed to the limited number of independent slip systems, in combination with the formation of fragile eutectic $\beta-\mathrm{Mg}_{17} \mathrm{Al}_{12}$ networks at grain boundaries. In an effort to overcome these limitations, spray forming followed by equal channel angular pressing (ECAP) was employed to obtain a unique bi-modal microstructure: coarse grains were separated and surrounded by deformation networks consisting of ultrafine-grained $\mathrm{Mg}$ with an average grain size of $0.6 \mu \mathrm{m}$ and ellipsoidal shaped $\beta-\mathrm{Mg}_{17} \mathrm{Al}_{12}$ particles with sizes of $200-300 \mathrm{~nm}$. Tensile tests revealed the advantage of this structure: a yield strength of $235 \mathrm{MPa}$ combined with an elongation to failure of $14 \%$; the values are significantly higher than those of their conventional counterparts (100 $\mathrm{MPa}-12 \%$, and $140 \mathrm{MPa}-5 \%)$. The underlying strengthening and deformation mechanisms of this particular microstructure are
\end{abstract}


discussed and analyzed.

Key words: Mg alloy, Spray forming, ECAP, Strengthening,

Deformation mechanisms, Ultra-fine grains

Corresponding author: yhzhao@njust.edu.cn

\section{Introduction}

$\mathrm{Mg}$ alloys have potential for wide industrial applications, including those in the automobile and aviation industries as well as in 3C products (computer, communication and consumer electronic), because of their low density, high specific strength, high specific stiffness along with good machinability, recyclability and damping capacity. However, there are still several issues that limit their widespread industrial applications $[1,2]$, one of which is their limited plasticity. Their hexagonal close-packed (hcp) crystal structure determines their limited independent slip systems, which is a major reason for their low plasticity. Other microstructural features may also significantly affect the plasticity. For example, in the $\mathrm{AZ}$ series of $\mathrm{Mg}$ alloys, which contain $\mathrm{Al}$ and $\mathrm{Zn}$ as solutes, continuous $\beta-\mathrm{Mg}_{17} \mathrm{Al}_{12}$ precipitates usually form networks at grain boundaries (GBs) during casting. These $\beta-\mathrm{Mg}_{17} \mathrm{Al}_{12}$ networks are fragile and tend to initiate cracks during subsequent deformation [3], which further lowers the limited plasticity. In addition, the eutectic $\beta-\mathrm{Mg}_{17} \mathrm{Al}_{12}$ phase also behaves as a cathodic phase, which accelerates the corrosion of $\alpha-\mathrm{Mg}$ matrix [4].

It is well known that rapid solidification techniques such as spray forming can overcome some of the problems associated with conventional casting techniques. For examples, previous studies on aluminum and iron-based alloys prepared by spray forming [5-7] revealed significant reduction in grain size and micro-segregation, which consequently led to enhancement of mechanical properties. However, review of published studies $[8,9]$ also shows that spray formed materials frequently contain a high volume fraction of pores which limit their ductility. Approaches to solve the porosity problem include extrusion, hot/cold roll or iso-static pressing, heat treatment, and forging following spray forming [10-13]. In reference [14], AZ91 prepared by spray forming and extrusion exhibited outstanding combinations of mechanical 
properties with a tensile ultimate strength (UTS) of $435 \mathrm{MPa}$, and YS of $360 \mathrm{MPa}$, and elongation to failure (EF) of 9.2\%, whereas the hot-rolled AZ91 alloy [15] exhibited a UTS of $345 \mathrm{MPa}$ and a YS of $297 \mathrm{MPa}$.

Severe plastic deformation (SPD) techniques, such as equal channel angular pressing (ECAP), have been effectively used to refine the overall microstructure of copper [16, 17], aluminum [18], titanium [19], nickel [20], Mg [21] and other metals $[22,23]$. In the case of hcp metals such as Mg, ECAP processing has been reported to have the following effects. First, grain refinement; this is noteworthy because it is difficult to refine $\mathrm{Mg}$ grains to sub-micron level via traditional processing, such as rolling, forging and extrusion. However, ECAP processing has been used to effectively produce homogeneous ultrafine grained (UFG) microstructures in a number of commercial $\mathrm{Mg}$ alloys including AZ31, AZ61 and AZ91 [24-26]. It is known that the extent of grain refinement increases with the number of ECAP passes. Moreover, to successfully process pure $\mathrm{Mg}$ by ECAP, temperature of $400{ }^{\circ} \mathrm{C}$ is required; in the case of $\mathrm{Mg}-0.9 \% \mathrm{Al}$ the required temperature is $200{ }^{\circ} \mathrm{C}$ [27]. These deformation temperatures are well above the recrystallization temperature $\left(\mathrm{T}_{\text {deformation }}>\right.$ $0.4 \mathrm{~T}_{\mathrm{M}}$ ), which inevitably leads to dynamic recrystallization (DRX). It has been reported [28-30] that the reduced grain size of $\mathrm{Mg}$ alloys is a consequence of accumulated large strain and DRX.

Second, SPD techniques can break down secondary phases. For Mg alloys with high levels of $\mathrm{Al}$, such as $\mathrm{AZ80}$ and $\mathrm{AZ91}$, a large volume fraction of $\beta-\mathrm{Mg}_{17} \mathrm{Al}_{12}$ precipitates continuously and grows directly on the Mg base plane, which belongs to the space group of $\mathrm{I} \overline{4} 3 \mathrm{~m}$ and has long-plate morphology, thus resulting in ineffective age hardening. During ECAP, the distribution, morphology and size of the precipitates can be optimized for better performance [31-33]. Specifically, the breakdown and redistribution of the precipitates by ECAP processing can reduce fracture initiation during deformation, and thereby enhance plasticity. For example, the YS, UTS and EF of the AZ91 alloy [34] were remarkably increased to 290, $417 \mathrm{MPa}$ and $8.45 \%$, respectively, after a two-step ECAP processing, mainly due to the refinement of grain and $\mathrm{Mg}_{17} \mathrm{Al}_{12}$ precipitates at GBs. Interestingly, several studies on $\mathrm{Mg}$ alloys [35-37] 
reported the presence of a bi-modal microstructure, that is CGs surrounded by a deformation layers near the original grain boundary that are composed of UFGs and a large numbers of second phase particles. Such a bi-modal microstructure has been reported to improve mechanical properties. For example [38], an ZK60 alloy processed by ECAP for 6 passes shows superplastic behavior with an elongation of $2040 \%$ at the tensile temperature of $473 \mathrm{~K}$, which was attributed to the bi-modal structure with an area fraction of $\sim 20 \%$ of large grains $(20-50 \mu \mathrm{m})$ and $\sim 80 \%$ of UFGs $(\sim 1 \mu \mathrm{m})$. Finally, SPD processing may modify the texture, which plays an important role in mechanical behavior of hcp metals. For example, ECAP processing and subsequent annealing have been reported to decrease the yield strength of an extruded AZ31 alloy due to texture modification [39]. A subsequent study by Lin et al. [40] found that the strength decrease was caused by the change of the Schmid factor due to tensile testing direction. The strong texture formation during the processing of $\mathrm{Mg}$ alloys may produce a strong anisotropy in mechanical properties [41].

A temperature step-down approach has been reported for ECAP processing of $\mathrm{Mg}$ alloys, in which lower processing temperature was used with increasing ECAP passes [42-44]. The advantage of this processing approach is that any DRX that occurs at higher temperatures effectively randomizes grain orientation and improves the plasticity for subsequent passes, while the lower temperatures at later passes generates a high defect density and fine grain sizes, which are beneficial to strength.

On the basis of the above published results, we hypothesize that it should be possible to implement a combination of ECAP and spray forming to simultaneously enhance the strength and ductility of Mg alloys. To verify this hypothesis, we processed an AZ80 Mg alloy by casting and spray forming and then ECAP processing via route $\mathrm{Bc}$ at various temperatures. Systematic microstructure studies on the extrusion direction (ED, X plane), flow direction (FD, Y plane) and longitudinal direction (LD, Z plane) were carried out. The Vickers microhardness and tensile properties were also determined. These experimental data were used to elucidate the underlying mechanisms that were responsible for the observed increase in strength and ductility. 


\section{Experimental procedures}

2.1 Sample preparation

Table 1. The chemical compositions (wt.\%) of AZ80 alloys in the present study.

\begin{tabular}{cccccccc}
\hline Sample & $\mathrm{Al}$ & $\mathrm{Zn}$ & $\mathrm{Mn}$ & $\mathrm{Cu}$ & $\mathrm{Si}$ & $\mathrm{Fe}$ & $\mathrm{Mg}$ \\
\hline As-sprayed & 7.89 & 0.39 & 0.23 & 0.05 & 0.02 & 0.01 & Bal. \\
As-cast & 8.03 & 0.41 & 0.18 & 0.03 & 0.02 & 0.02 & Bal. \\
\hline
\end{tabular}

The initial CG AZ80 Mg alloys were prepared by conventional casting followed by a homogenization at $420{ }^{\circ} \mathrm{C}$ for $6 \mathrm{~h}$ to eliminate the massive coarse $\beta-\mathrm{Mg}_{17} \mathrm{Al}_{12}$ network (hereafter, denoted as-cast) and by spray forming (hereafter, denoted as-sprayed). The chemical compositions of both as-cast and as-sprayed samples were determined by Inductively Coupled Plasma-Atomic Emission Spectrometry (Prodigy, American Leeman) and presented in Table 1. The ECAP processing procedure was: First, the as-sprayed and as-cast AZ80 samples were extruded at $300{ }^{\circ} \mathrm{C}$ with a rod diameter reduction from $20 \mathrm{~mm}$ to $16 \mathrm{~mm}$. Second, the extruded rods were subjected to ECAP processing to six passes via the route $\mathrm{Bc}$, in which the samples were rotated by $90^{\circ}$ in the same direction between two consecutive passes (hereafter, denoted as as-sprayed-ECAP and as-cast-ECAP, respectively). Three ECAP temperatures of $350{ }^{\circ} \mathrm{C}, 250{ }^{\circ} \mathrm{C}$ and $200{ }^{\circ} \mathrm{C}$ were used in turn for two passes, respectively. After ECAP, samples parallel to the ED, FD and LD were sectioned from the rods. For comparison, pre-ECAP samples were also sectioned parallel to the ED from the as-cast and as-sprayed materials.

\subsection{Microstructure characterization}

Microstructure analyses were performed by means of optical microscopy (OM), scanning electron microscopy (SEM), transmission electron microscopy (TEM) and X-ray diffraction (XRD). The billets were ground with 800 and 1200 grit $\mathrm{SiC}$ abrasive paper and then mechanically polished using diamond slurries (3 and $1 \mu \mathrm{m})$ with oil-based medium. The polished specimens were finally etched at room temperature with a solution containing $2 \%$ oxalic acid and nitric acid $2 \%$ for 20 s. The OM and 
SEM observations were carried out at true color confocal microscope system (Axio CSM 700) and FEI, Quanta250 with energy dispersive spectrometer (EDS) detector of Oxford with an accelerating voltage of $20 \mathrm{kV}$. TEM specimens were first ground to a thin foil with a thickness of $60 \mu \mathrm{m}$, dimpled to $30 \mu \mathrm{m}$, and then milled to a thickness that is transparent to electron by precision ion milling (GATAN 691) with an $\mathrm{Ar}^{+}$ accelerating voltage of $3.2 \mathrm{kV}$ at room temperature. The TEM, high-resolution TEM (HREM) and scanning TEM (STEM) were performed using a FEI Techai G2 F30 microscope operating at $300 \mathrm{kV}$. Macroscopic phase identification by XRD was performed using a Bruker D8 Discover X-ray machine with $\mathrm{Cu}-\mathrm{K} \alpha$ radiation at $40 \mathrm{kV}$ and $40 \mathrm{~mA}$. Oxygen analysis of spray formed sample was conducted with X-ray Photoelectron Spectroscopy (XPS, ULVAC-PHI П, Japan) using a monochromatic Al $\mathrm{K} \alpha$ source $(15 \mathrm{kV}, 45 \mathrm{~W})$. Before XPS test, Ar ion sputtering was prepared for surface treatment, with ion gun voltage of $4 \mathrm{kV}$ and gun angle of $45^{\circ}$. The whole XPS experiment was conducted under vacuum degree below $5 \times 10^{-8}$ torr and the lower limit of detection could reach zero point one percent (0.1 at.\%).

\subsection{Mechanical properties}

Vickers microhardnesses were measured on nano-indenter (HMV-G 21DT, Shimazdu) with a load of $980.7 \mathrm{mN}$ and dwell time of $10 \mathrm{~s}$. Each $\mathrm{Hv}$ value was averaged from at least 25 data points with a standard deviation of $\pm 2 \%$.

Tensile tests were carried out at room temperature with an initial quasi-static strain rate of $1 \times 10^{-3} \mathrm{~s}^{-1}$. The strain was measured by calculation of crosshead movement using computer software. Flat dog-bone shaped tensile specimens with gauge dimensions of $1 \times 1 \times 4 \mathrm{~mm}^{3}$ were sectioned by electro spark machining from the central regions of the round bars with the gauge axis parallel to the ED. Each tensile test result was repeated 3 times to assure the reproducibility of the data.

\section{Experimental results}

\subsection{Microstructures}

The OM observations on the original as-sprayed and as-cast samples are shown in Figure $1 \mathrm{a}$ and $\mathrm{b}$. The grain size of the as-sprayed and as-cast samples are 
approximately 40 and $60 \mu \mathrm{m}$, respectively, measured using the average linear intercept method. In the as-sprayed sample, there are large precipitates with a diameter of several micrometers and some smaller particles at both GBs and grain interiors. For the as-cast sample, most large precipitates are located at the GBs. Overall, the spray forming produced finer microstructures than traditional casting.

Figure $1 \mathrm{~d}$ and e depicts the OM images of the as-sprayed-ECAP and as-cast-ECAP samples, respectively, in different directions of ED, FD and LD. Both samples exhibit a structure feature where coarse $\mathrm{Mg}$ grains were separated and surrounded by deformation networks. The sizes of the coarse-grains range from 20 to $30 \mu \mathrm{m}$ in the as-sprayed-ECAP samples and from 40 to $50 \mu \mathrm{m}$ in the as-cast-ECAP sample; these grain sizes are significantly smaller than those samples that were not processed via ECAP. The amount and size of the large precipitates with diameters of several micrometers observed in samples without ECAP appear to remain unchanged following ECAP, suggesting that ECAP did not break up these large precipitates.

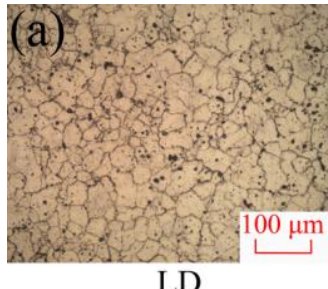

LD

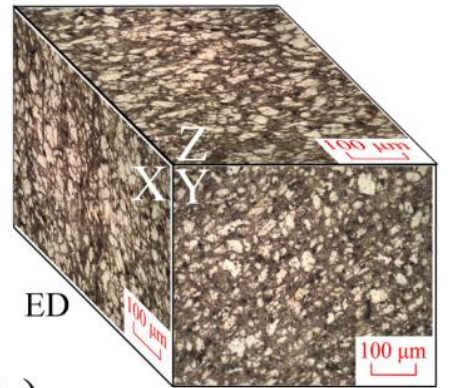

(c)

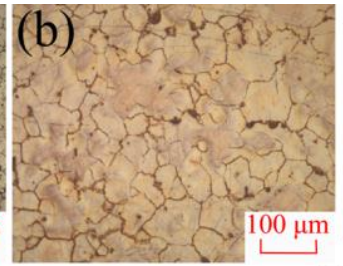

LD

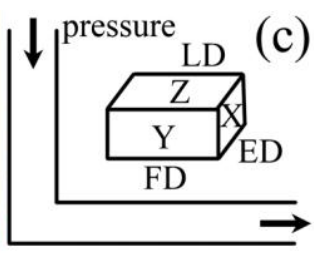

(c)

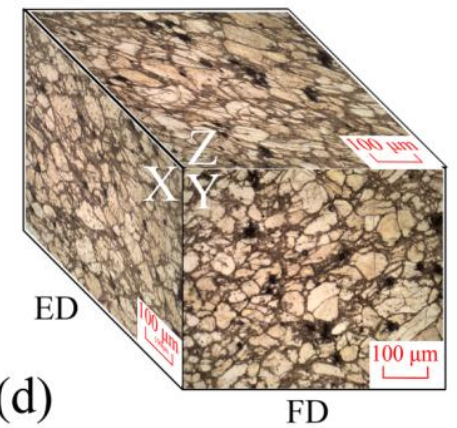

(d)

FD

Figure 1. Optical micrograph (OM) of (a) as-sprayed, (b) as-cast AZ80 alloys; (c) schematic of sectioned samples corresponding to the ECAP-processed billet; OM of (c) as-sprayed-ECAP and (d) as-cast-ECAP AZ80 alloys observed from the ED (X plane), FD (Y plane) and LD (Z plane). The ED, FD and LD here indicate for the extrusion direction, flow direction and longitudinal direction, respectively. 

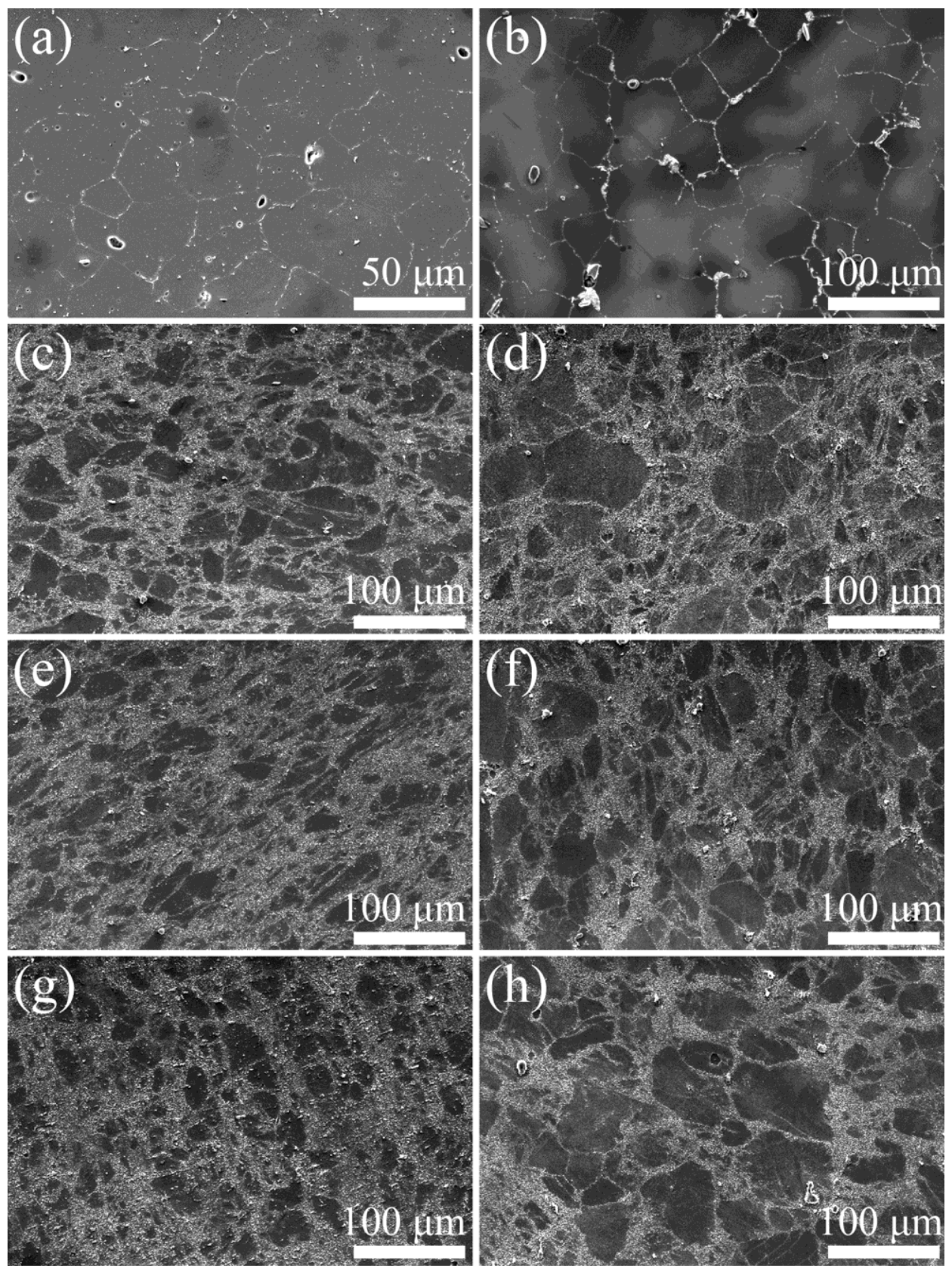

Figure 2. SEM images of (a) as-sprayed, (b) as-cast AZ80 alloys, and the as-sprayed-ECAP (c, e and g) as well as the as-cast-ECAP (d, f and h) AZ80 alloys along the ED (c, d), FD (e, f) and LD (g, h).

The SEM images of the as-sprayed and as-cast samples are shown in Figure 2a and b. The SEM results confirmed microstructure characteristics observed by OM (Fig. 1a and b): precipitates formed at GBs and in grain interiors for the as-sprayed sample, but primarily at $\mathrm{GBs}$ for the as-cast sample. In addition, $\beta-\mathrm{Mg}_{17} \mathrm{Al}_{12}$ 
precipitated at the GBs to form almost continuous networks for both as-sprayed and as-cast samples. Figure 2c-h displays six individual SEM images viewed from different directions of two specimens: Images $\mathrm{c}$, e and $\mathrm{g}$ are for ED, FD and LD of as-sprayed-ECAP sample, and $\mathrm{d}, \mathrm{f}$ and $\mathrm{h}$ for ED, FD and LD of as-cast-ECAP sample. A bi-modal microstructure can be seen: CG Mg grains were separated and surrounded by deformation networks with UFGs. This microstructure can also be regarded as large soft grains embedded in harder UFG matrix, similar to the "harmonic structure" reported earlier [45]. In addition, there exists white ellipsoidal particles approximately 10-30 $\mu \mathrm{m}$ within the deformed layer. This is more clearly seen in Figure $3 \mathrm{a}$ and $\mathrm{b}$ for the as-sprayed-ECAP sample in ED with larger magnifications. The ellipsoidal shaped particles have sizes in the range of 200-300 $\mathrm{nm}$. Moreover, a few larger polygon-shaped particles several micro-meters in size can be seen in the vicinity of the agglomerated ultrafine particles.

To determine the compositions of ultrafine and coarse particles, we performed element point scanning with EDS, and results are shown in Figure $3 \mathrm{c}$ and $\mathrm{d}$ for the particles labeled by A and B. The EDS results suggest that the ultrafine particles are the $\beta-\mathrm{Mg}_{17} \mathrm{Al}_{12}$ phase and that the coarse particles are likely the intermetallic compound with chemical formula of $\mathrm{Al}_{8} \mathrm{Mn}_{5}$. Similar results have also been reported $[47,48]$. In addition, we further performed $\mathrm{Mg}, \mathrm{Al}$ and $\mathrm{Mn}$ elemental mapping in the area $\mathrm{C}$ highlighted with a red rectangle in Figure $3 \mathrm{~b}$, as shown in Figure 3e. These results reveal that the coarse particle contains both $\mathrm{Al}$ and $\mathrm{Mn}$. From over 30 similar SEM images shown in Figure $2 \mathrm{c}-\mathrm{h}$, the volume fraction of $\beta-\mathrm{Mg}_{17} \mathrm{Al}_{12}$ phase was calculated through pixel dots by Image Pro Plus professional software and was determined to be $16 \%$ for the as-sprayed-ECAP and $13 \%$ for the as-cast-ECAP samples. In the discussion on mechanical behavior that follows, we do not take into account the $\mathrm{Al}_{8} \mathrm{Mn}_{5}$ phase, given their large sizes and small volume fraction. XRD analyses confirm the presence of $\beta-\mathrm{Mg}_{17} \mathrm{Al}_{12}$ and $\mathrm{Al}_{8} \mathrm{Mn}_{5}$ (see Fig. 4). In addition, after ECAP, the corresponding $\beta-\mathrm{Mg}_{17} \mathrm{Al}_{12}$ peak height dramatically increased, which indicates that ECAP promoted the precipitation of a large number of $\mathrm{Mg}_{17} \mathrm{Al}_{12}$ particles from the $\alpha-\mathrm{Mg}$ matrix. 

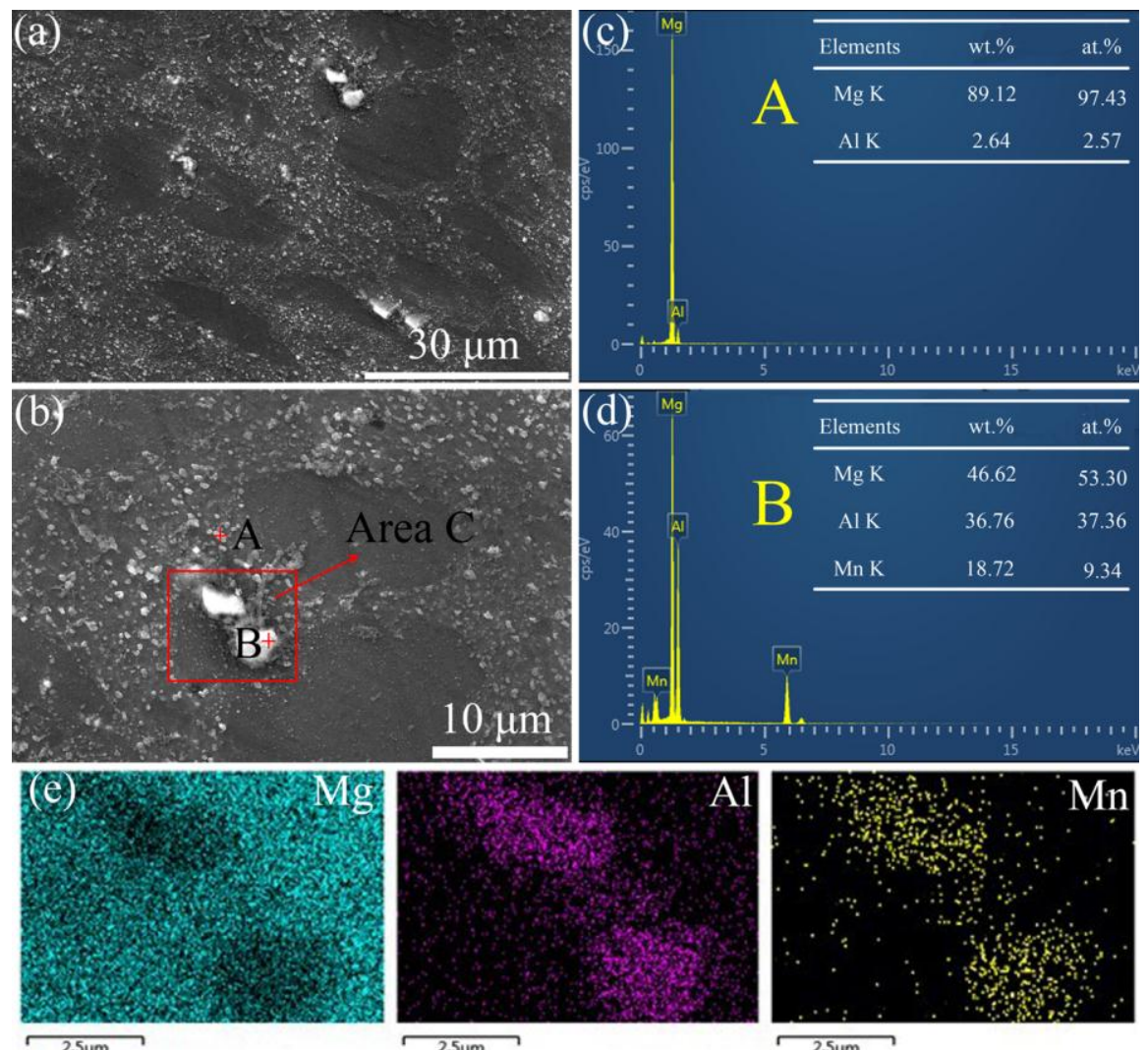

Figure 3. SEM images of (a) as-sprayed-ECAP sample in the ED and (b)

high-magnification image of $\beta-\mathrm{Mg}_{17} \mathrm{Al}_{12}$ (marked as " $\mathrm{A}$ ") and $\mathrm{Al}_{8} \mathrm{Mn}_{5}$ (marked as "B") particles in image (a); (c) and (d): elemental spectrums provided by EDS in point scan mode and elemental concentrations in wt.\% and at.\% for particle A and B. (e):

elements $\mathrm{Al}, \mathrm{Mg}$ and $\mathrm{Mn}$ map scan of $\mathrm{Al}_{8} \mathrm{Mn}_{5}$ particles in area $\mathrm{C}$ marked in image (b).

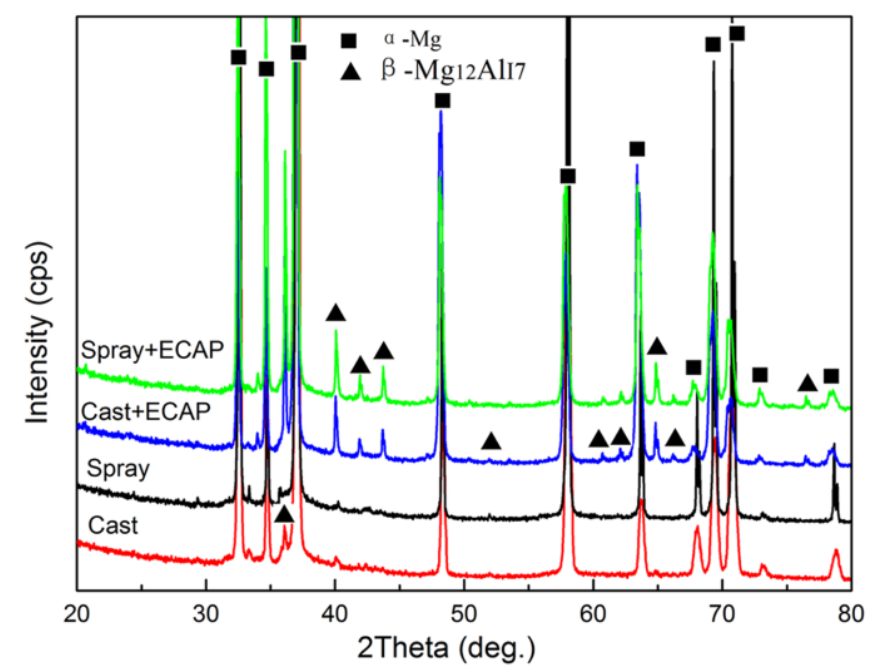

Figure 4. The XRD of the as-sprayed, as-cast, as-sprayed-ECAP and as-cast-ECAP AZ80 alloys. 

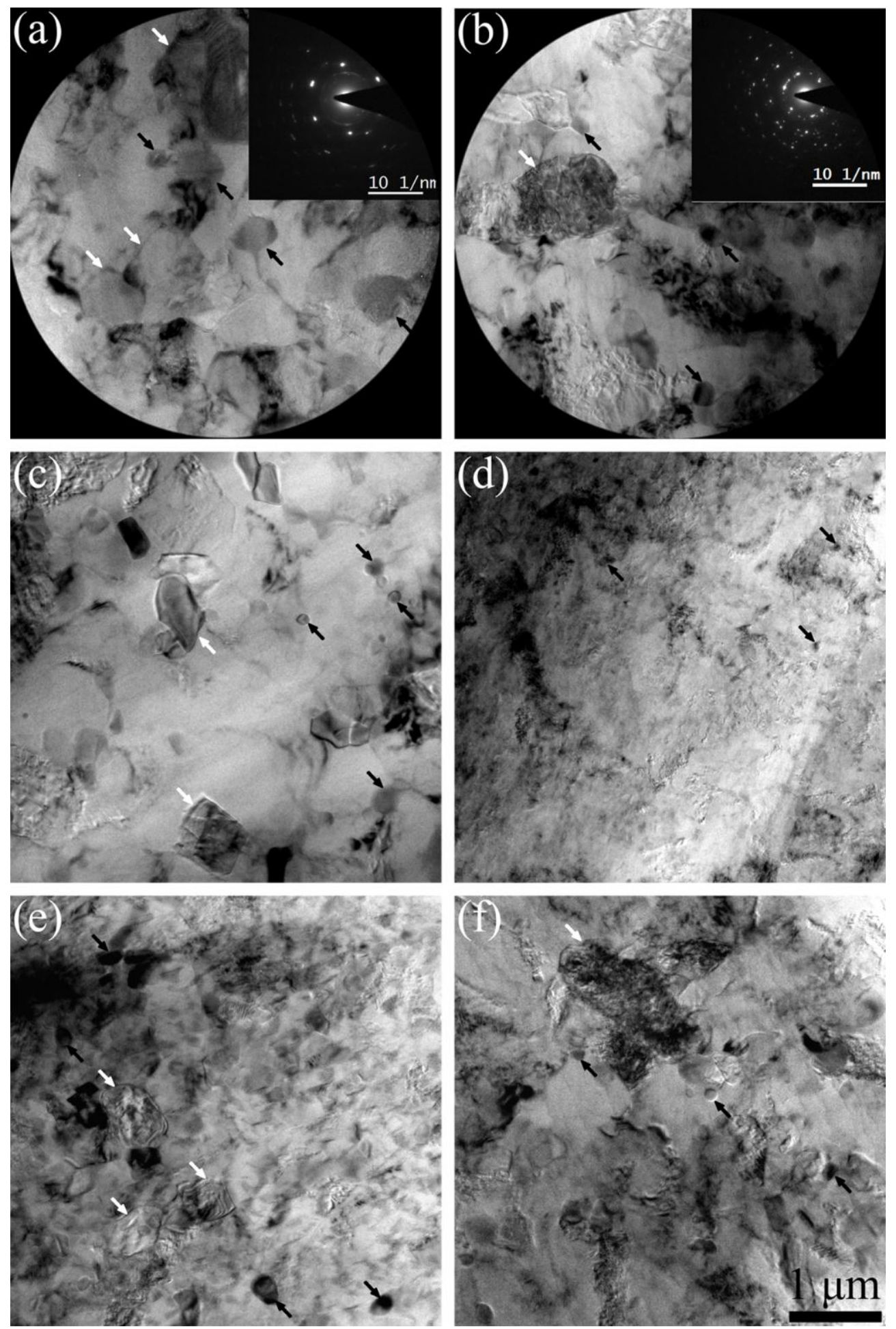

Figure 5. TEM bright field micrographs in the ED (a,b), FD (c,d) and LD (e,f) of as-sprayed-ECAP (a, c and e) and as-cast-ECAP (b, d and f) samples; the insets within (a) and (b) are their corresponding SADPs; the white arrows refer to $\alpha-\mathrm{Mg}$ grains and the black arrows point to $\beta-\mathrm{Mg}_{17} \mathrm{Al}_{12}$ particles. 


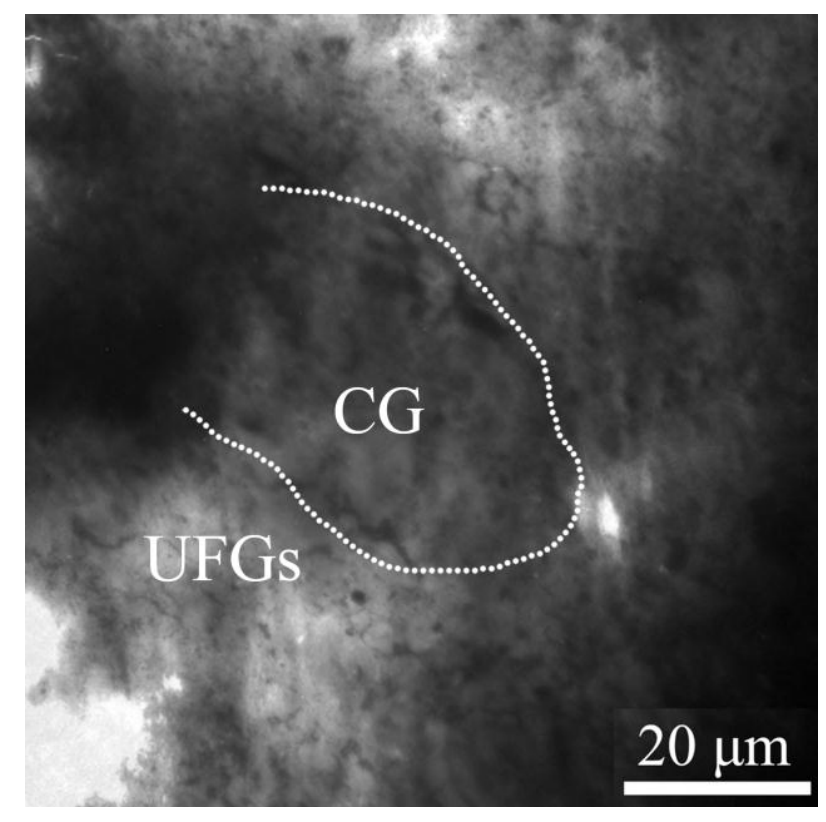

Figure 6. TEM micrograph showing a microstructure with a large grain embedded in the UFG matrix as observed in the FD of the as-cast-ECAP sample.

To further study the microstructure within the deformed UFG networks, TEM observations were carried out. Figure 5 presents the TEM images of AZ80 alloys in ED, FD, and LD of as-sprayed-ECAP (a, c, e) and as-cast-ECAP (b, d, f) samples. The white arrows and black arrows highlight the $\alpha-\mathrm{Mg}$ grains and $\beta-\mathrm{Mg}_{17} \mathrm{Al}_{12}$ particles, respectively. It is evident that the UFG $\alpha-\mathrm{Mg}$ grains were formed after ECAP: the average grain size is 0.6 and $0.8 \mu \mathrm{m}$ for the as-sprayed-ECAP and as-cast-ECAP samples, respectively, as measured from over 200 grains for each direction in TEM micrographs. The insets in Figure 5a and $\mathrm{b}$ are their corresponding selected area diffraction patterns (SADP). They show evident diffraction spots, indicating a texture among the UFGs. Moreover, ellipsoidal shaped $\beta-\mathrm{Mg}_{17} \mathrm{Al}_{12}$ particles with sizes ranging from several tens to hundreds of nanometers were observed, as marked by the black arrows. It is difficult to locate any complete $\alpha-\mathrm{Mg}$ grain in the Figures $5 \mathrm{~d}$ and $\mathrm{f}$. It is speculated that those images were taken from the $\mathrm{CG}$ region or transition region of the bi-modal structure. The micrograph in Figure 6, obtained from the FD of as-cast-ECAP sample, clearly shows the bi-modal structure. The CGs with the size of $30 \mu \mathrm{m}$ were surrounded by an UFG region with a width of $10 \mu \mathrm{m}$ corresponding to the deformation UFG layer as seen in SEM images (Fig. 2). 

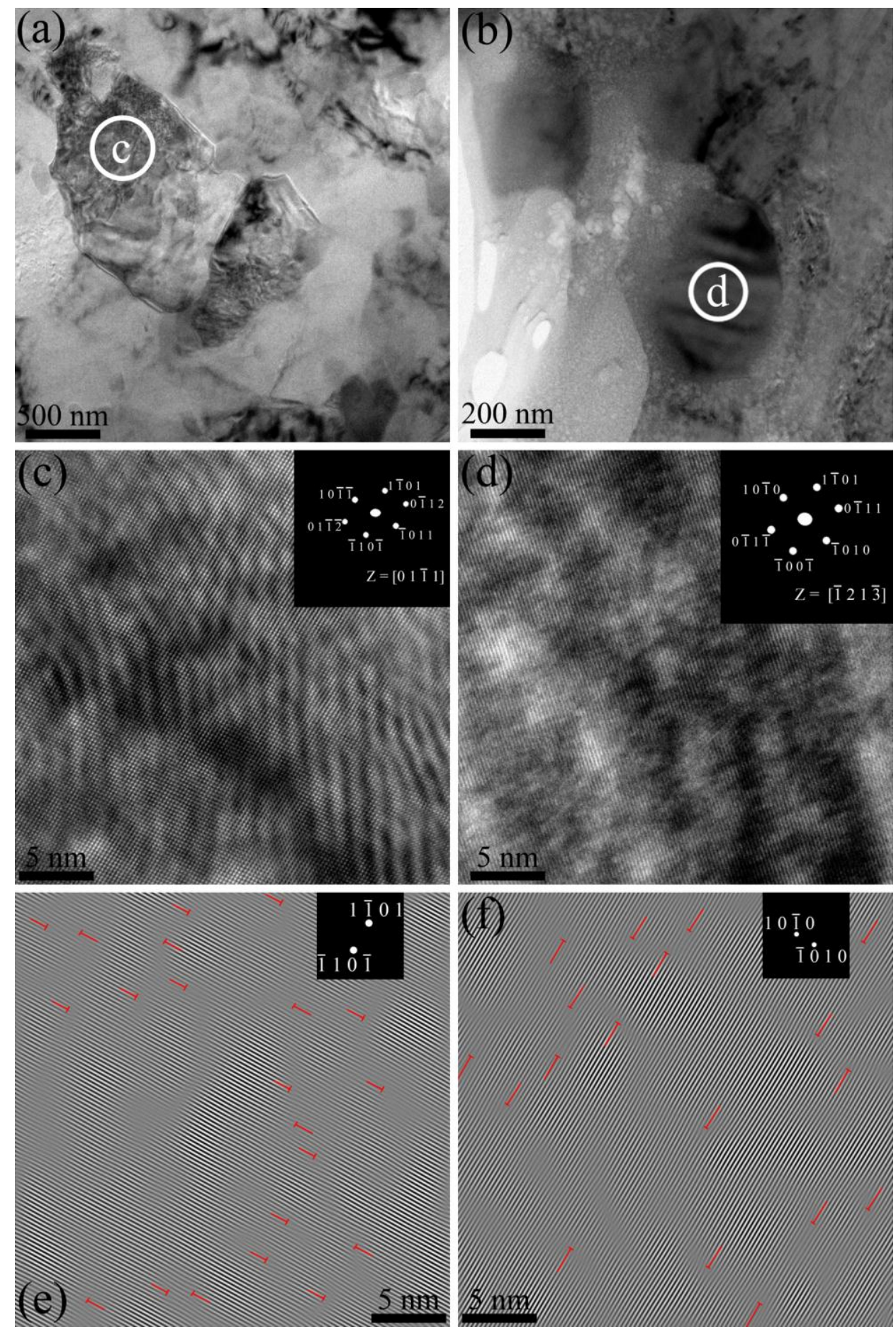

Figure 7. TEM bright field micrographs of $\alpha-\mathrm{Mg}$ grains in the ED of the as-sprayed-ECAP (a) and the as-cast-ECAP (b) samples; (c) and (d): HREM images of white solid line circle area in images (a) and (b), the insets of diffraction patterns

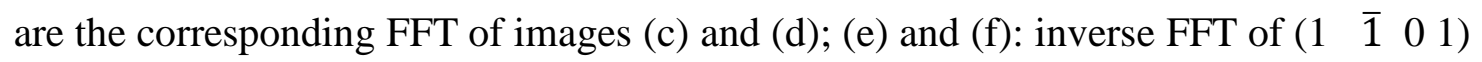
and (1 $\left.\begin{array}{lll}0 & \overline{1} & 0\end{array}\right)$ lattice planes of (c) and (d) for the as-sprayed-ECAP and the as-cast-ECAP samples. the edge dislocations are highlighted by red" $\perp$ ”symbols. 
Higher-magnification TEM images of matrix grains in ED of as-sprayed-ECAP and as-cast-ECAP are shown in Figures $7 \mathrm{a}$ and b. HREM images are shown in Figures $7 \mathrm{c}$ and $\mathrm{d}$, corresponding to the white solid line circled region in Figures $7 \mathrm{a}$ and $\mathrm{b}$, respectively. The calibrated diffraction pattern insets are the corresponding Fourier transformation (FFT) patterns of the HREM images. There are three pairs of parallel lattice planes in the diffractogram. The corresponding inverse FFT pattern of one pair of parallel lattice planes is displayed in Figure $7 \mathrm{e}$ and $\mathrm{f}$, the $\left(\begin{array}{llll}1 & \overline{1} & 0 & 1\end{array}\right)$ and $\left(\begin{array}{llll}1 & 0 & \overline{1} & 0\end{array}\right)$ planes for the as-sprayed-ECAP and as-cast-ECAP, respectively. In Figure 7e and f, dislocations were marked with " $\perp$ " in red, at the points where the extra atomic planes terminate. In order to quantify dislocation density, the numbers of dislocation per unit area were calculated, based on more than thirty images. The calculated numbers of dislocations per unit area are $2.1 \times 10^{13}$ and $1.1 \times 10^{13}$ for the as-sprayed-ECAP and as-cast-ECAP specimens, respectively, as summarized in Table 2.
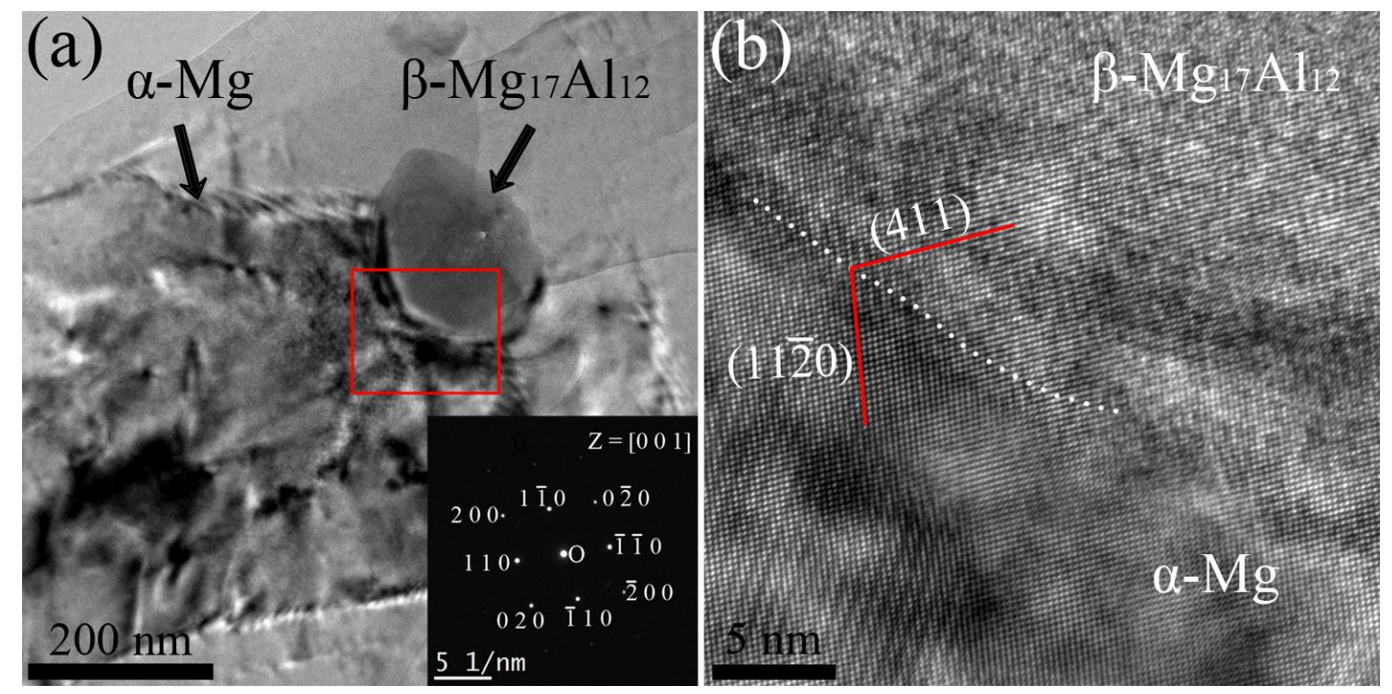

Figure 8. (a)TEM micrograph of $\alpha-\mathrm{Mg}$ and $\beta-\mathrm{Mg}_{17} \mathrm{Al}_{12}$ particles in the $\mathrm{ED}$ of the as-sprayed-ECAP sample, the inset shows the corresponding diffraction pattern of $\beta-\mathrm{Mg}_{17} \mathrm{Al}_{12}$ particle; (b) HREM image of the red rectangular region in image (a).

Figure 8a illustrates TEM bright-field image of the matrix and the $\beta-\mathrm{Mg}_{17} \mathrm{Al}_{12}$ particle in ED of as-sprayed-ECAP sample. The calibrated diffraction pattern of 
$\beta-\mathrm{Mg}_{17} \mathrm{Al}_{12}$ phase shows that these images were taken with electron beam in direction

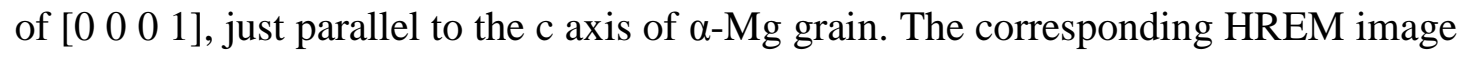
of the red rectangle region is shown in Figure 8b. The inter-planar spacing of the $\mathrm{Mg}$ matrix and the second phase were measured to be $0.243 \mathrm{~nm}$ and $0.248 \mathrm{~nm}$, which

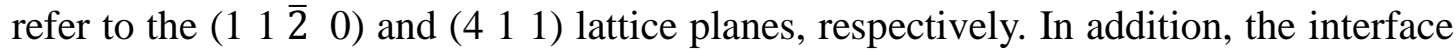
between the second phase and the matrix is smooth and the GBs could be barely observed. According to a previous study [46], the two predominant orientation relationships (ORs) between the $\beta$-phase and $\mathrm{Mg}$ matrix are $\left(\begin{array}{llll}0 & 0 & 0 & 1\end{array}\right)_{\mathrm{m}} / /\left(\begin{array}{lll}1 & \overline{1} & 1\end{array}\right)_{\mathrm{p}},\left[\begin{array}{ll}1\end{array}\right.$ $\left.\begin{array}{lll}\overline{2} & 1 & 0\end{array}\right]_{\mathrm{m}} / /\left[\begin{array}{lll}1 & \overline{1} & \overline{2}\end{array}\right]_{\mathrm{p}}$ and $\left(\begin{array}{llll}1 & \overline{2} & 1 & 1\end{array}\right)_{\mathrm{m}} / /\left(\begin{array}{lll}1 & 1 & 0\end{array}\right)_{\mathrm{p}},\left[\begin{array}{llll}1 & 0 & \overline{1} & 0\end{array}\right]_{\mathrm{m}} / /\left[\begin{array}{lll}1 & 1 & 0\end{array}\right]_{\mathrm{p}}$, both of which are incoherent interfaces. However, similar findings of (4 11 1) lattice planes have been reported in spray-formed AZ31 [47], raising a speculation as to whether this observation is characteristic of the spray formed materials; work in this area is continuing. The STEM images shown in Figure $9 \mathrm{a}$ and $\mathrm{b}$ were taken from the $\beta-\mathrm{Mg}_{17} \mathrm{Al}_{12}$ particles present in ED of the as-sprayed-ECAP and as-cast-ECAP specimens, respectively. The average particle sizes are about 240 and $300 \mathrm{~nm}$, respectively. Results from extensive statistical analyses of microstructure characteristics are summarized in Table 2, including the average $\mathrm{Mg}$ grain size in the $\operatorname{ED}(0.62$ and $0.73 \mu \mathrm{m}), \mathrm{FD}(0.50$ and $0.91 \mu \mathrm{m})$ and $\operatorname{LD}(0.76$ and $0.82 \mu \mathrm{m})$ for the as-sprayed-ECAP and as-cast-ECAP specimens.

Table 2. Results from extensive statistical analyses of microstructure characteristics of the as-sprayed-ECAP and as-cast-ECAP samples: average size of $\alpha-\mathrm{Mg}$ grains $\mathrm{d}_{1}$ and $\beta-\mathrm{Mg}_{17} \mathrm{Al}_{12}$ particles $\mathrm{d}_{2}$ and the numbers of dislocation per unit area $\rho_{\mathrm{ds}}$.

\begin{tabular}{ccccccc}
\hline & \multicolumn{3}{c}{ as-sprayed-ECAP } & \multicolumn{3}{c}{ as-cast-ECAP } \\
& ED & FD & LD & ED & FD & LD \\
\hline$\overline{\mathrm{d}_{1}}(\mathrm{um})$ & 0.62 & 0.50 & 0.76 & 0.73 & 0.91 & 0.82 \\
$\overline{\mathrm{d}_{2}}(\mathrm{um})$ & & 0.24 & & & 0.30 & \\
$\overline{\rho_{\mathrm{ds}}}\left(/ \mathrm{m}^{2}\right)$ & & $2.1 \times 10^{13}$ & & & $1.1 \times 10^{13}$ & \\
\hline
\end{tabular}



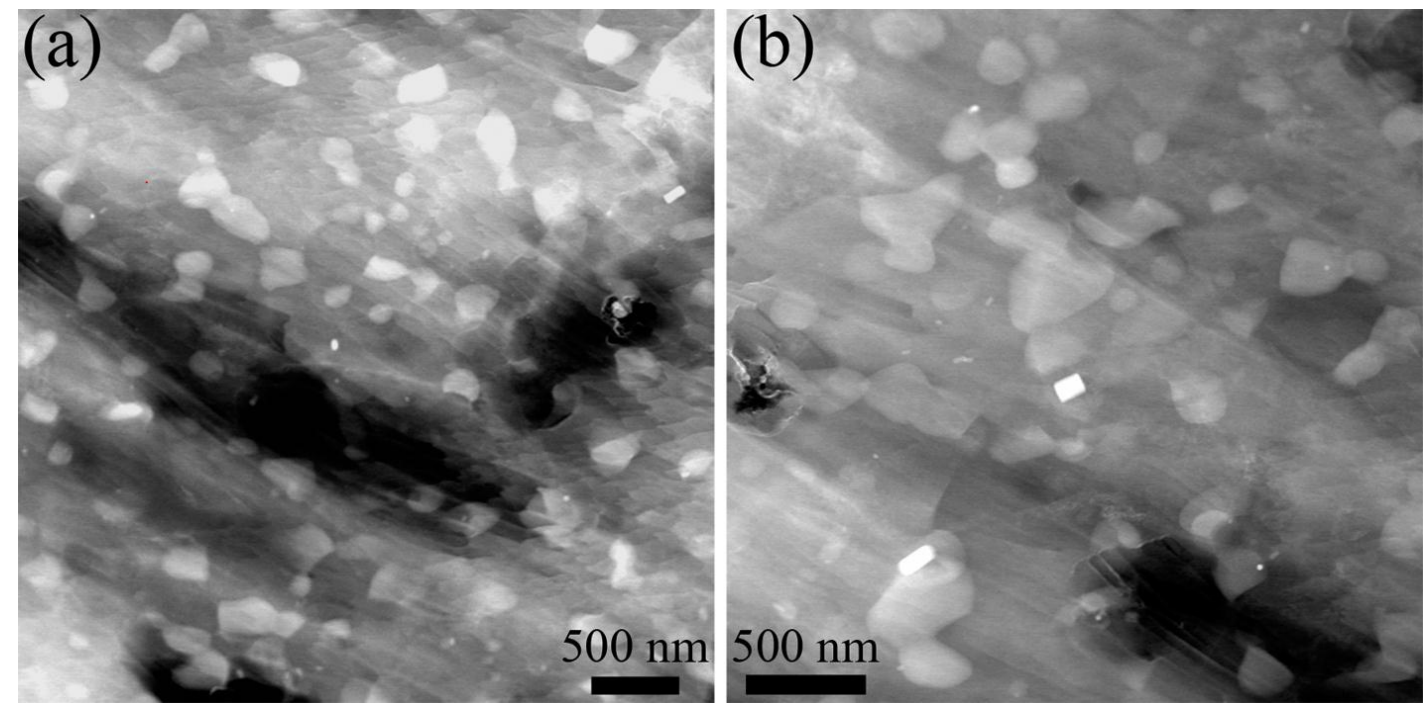

Figure 9. The STEM micrographs of $\beta-\mathrm{Mg}_{17} \mathrm{Al}_{12}$ particles in the $\mathrm{ED}$ of (a) the as-sprayed-ECAP and (b) the as-cast-ECAP samples

\subsection{Mechanical properties}

Table 3. Hv0.1 mircohardness values of the as-sprayed, as-cast, as-sprayed-ECAP and as-cast-ECAP samples. The dwell time is 10 seconds, each value was averaged from 25 data with an uncertainty of $\pm 2 \%$.

\begin{tabular}{cccc}
\hline & ED & FD & LD \\
\hline as-sprayed & 64 & & \\
as-cast & 57 & & \\
as-sprayed-ECAP & 115 & 127 & 112 \\
as-cast-ECAP & 104 & 117 & 103 \\
\hline
\end{tabular}

The results of microhardness measurements are summarized in Table 3. ECAP dramatically increased the microhardness of the original as-sprayed and as-cast samples. In both as-sprayed-ECAP and as-cast-ECAP samples, highest $\mathrm{HV}$ values appear in the FD, followed by samples in ED and then LD, which is consistent with the mechanical properties of ECAP-processed AZ31B alloy [41]. However, the outstanding mechanical properties of samples in FD was attributed to twinning-dominated mechanism, which rarely occurs in UFG Mg alloys [48, 49]. Additionally, the incremental grain refinement using the temperature step-down 
method has been reported to suppress twinning [44]. Our TEM investigation failed to identify deformation twins in our UFG Mg alloys, which are consistent with the literature.

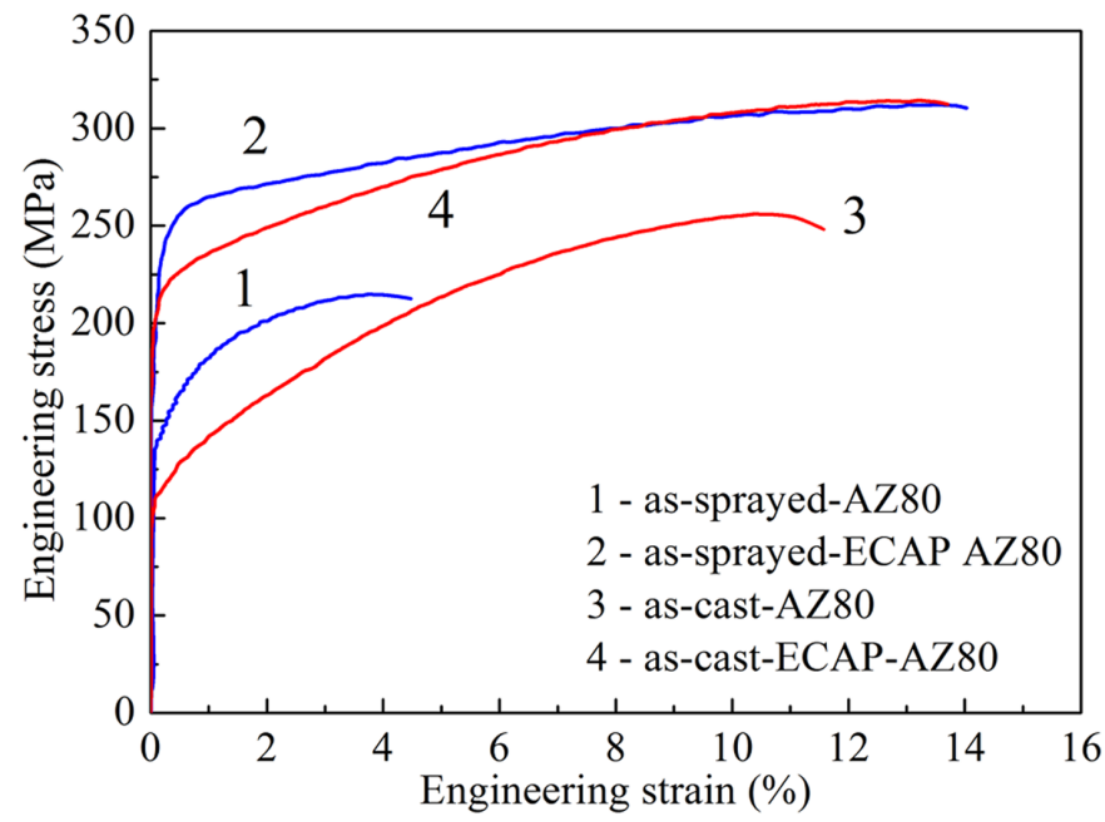

Figure 10. The engineering stress-true strain curves of the as-sprayed, as-cast, as-sprayed-ECAP and as-cast-ECAP AZ80 Mg alloys along the extrusion direction.

Table 4. Tensile properties for AZ80 alloy at room temperature: the ultimate tensile strength (UTS), yield strength (YS) and elongation to failure (EF).

\begin{tabular}{ccccc}
\hline & as-sprayed & as-sprayed-ECAP & as-cast & as-cast-ECAP \\
\hline YS (MPa) & 140 & 235 & 100 & 200 \\
UTS (MPa) & 225 & 305 & 255 & 315 \\
EF (\%) & 5 & 14 & 12 & 14 \\
\hline
\end{tabular}

The engineering true stress-strain curves of the as-cast, as-sprayed, and ECAPed samples along the extrusion direction (in Y plane) are shown in Figure 10. Table 4 lists the YS, UTS and EF (ductility, elongation to failure) of all samples. The data show that the EF of the as-sprayed sample (5\%) is much smaller than that of the as-cast sample (12\%), which is likely due to the presence of porosity in the as-sprayed material. While the YS of the as-sprayed sample (140 MPa) is higher than that of the 
as-cast sample (100 MPa), consistent with its finer grains and precipitate, as shown in Figure 1. After further ECAP processing, both YS and EF are improved significantly for both the as-sprayed and as-cast samples. For example, the YS and EF of the as-cast sample were increased to $200 \mathrm{MPa}$ and 14\%, respectively, by ECAP; and those of the as-sprayed sample to $235 \mathrm{MPa}$ and $14 \%$, respectively. In other words, the combination of spray forming and ECAP process achieved the best YS and EF properties (235 $\mathrm{MPa}$ and 14\%). As discussed later, these superior mechanical properties are associated with the unique microstructure formed by ECAP.

\subsection{Oxygen analysis}

During the spray forming process, oxygen is generally present, and therefore oxide phases will form. In order to evaluate oxygen concentration in the as-sprayed sample, ion sputtering and XPS were carried out. As shown in Figure 11a, the atomic concentration of $\mathrm{Mg}$ and $\mathrm{O}$ varies with sputter time. Sputtering for 4 minutes decreased atomic concentration of $\mathrm{O}$ from $36.2 \%$ to $0 \%$ while the atomic concentration of $\mathrm{Mg}$ increased from $16.8 \%$ to $100 \%$, and the atomic concentration remained constant during further sputtering. This suggests that the surface oxidation layer was removed totally after sputtering for 4 minutes. In order to understand the variation of atomic concentration of $\mathrm{Mg}$ and $\mathrm{O}$ during sputtering, point scanning with beam spot of $200 \mu \mathrm{m}$ was conducted every minute within sputter time of 4 minutes, as shown in Figure $11 \mathrm{~b}$ and c. Narrow band spectrum of $\mathrm{Mg} 2 \mathrm{~s}$ is shown in Figure 11b, it can be seen that only one peak with a binding energy $\left(\mathrm{P}_{\mathrm{BE}}\right)$ of about $89 \mathrm{eV}$ appeared at 1 minute, while at two minutes another peak appeared $\left(\mathrm{P}_{\mathrm{BE}}=102 \mathrm{eV}\right)$ and it remained basically unchanged with sputter time prolonged to 4 minutes. In Figure 11c of narrow band spectrum of $\mathrm{O} 1 \mathrm{~s}$, there is a peak with $\mathrm{P}_{\mathrm{BE}}=532 \mathrm{eV}$ at 1 minute and this peak disappeared when prolonged to 2 minutes. From 2 minutes to 4 minutes, the three curves almost remain unchanged. When the sample was sputtered for 5 minutes, it was scanned again in point mode. The narrowband spectrum of Mg 2s (Fig. 11d) shows the same peak position as in the 4-minutes sputtering (Fig. 11b). For narrow band spectrum of $\mathrm{O}$ 1s shown in Figure 11e, no obvious peaks could be found, which means that the $\mathrm{O}$ concentration is lower than the detection limit of XPS. 
Based on $\mathrm{Mg}$ and $\mathrm{O}$ standard spectra for XPS analysis, $\mathrm{P}_{\mathrm{BE}}=89 \mathrm{eV}$ corresponds to $\mathrm{Mg}, \mathrm{P}_{\mathrm{BE}}=102 \mathrm{eV}$ to $\mathrm{Mg}^{2+}$, and $\mathrm{P}_{\mathrm{BE}}=532 \mathrm{eV}$ to $\mathrm{O}^{2-}$. These results indicates that 1) there were negligible oxides (below 0.1 at.\%) formed during spray forming; 2) the valence states of $\mathrm{Mg}$ and $\mathrm{Mg}^{2+}$ confirm that $\mathrm{Mg}$ exists in $\alpha-\mathrm{Mg}$ and $\beta-\mathrm{Mg}_{17} \mathrm{Al}_{12}$ phase, which is consistent with SEM and TEM results. As for as-sprayed-ECAP sample, the as-sprayed sample has negligible oxides and ECAP processing will not introduce $\mathrm{O}$, so the effect of oxides could also be negligible.
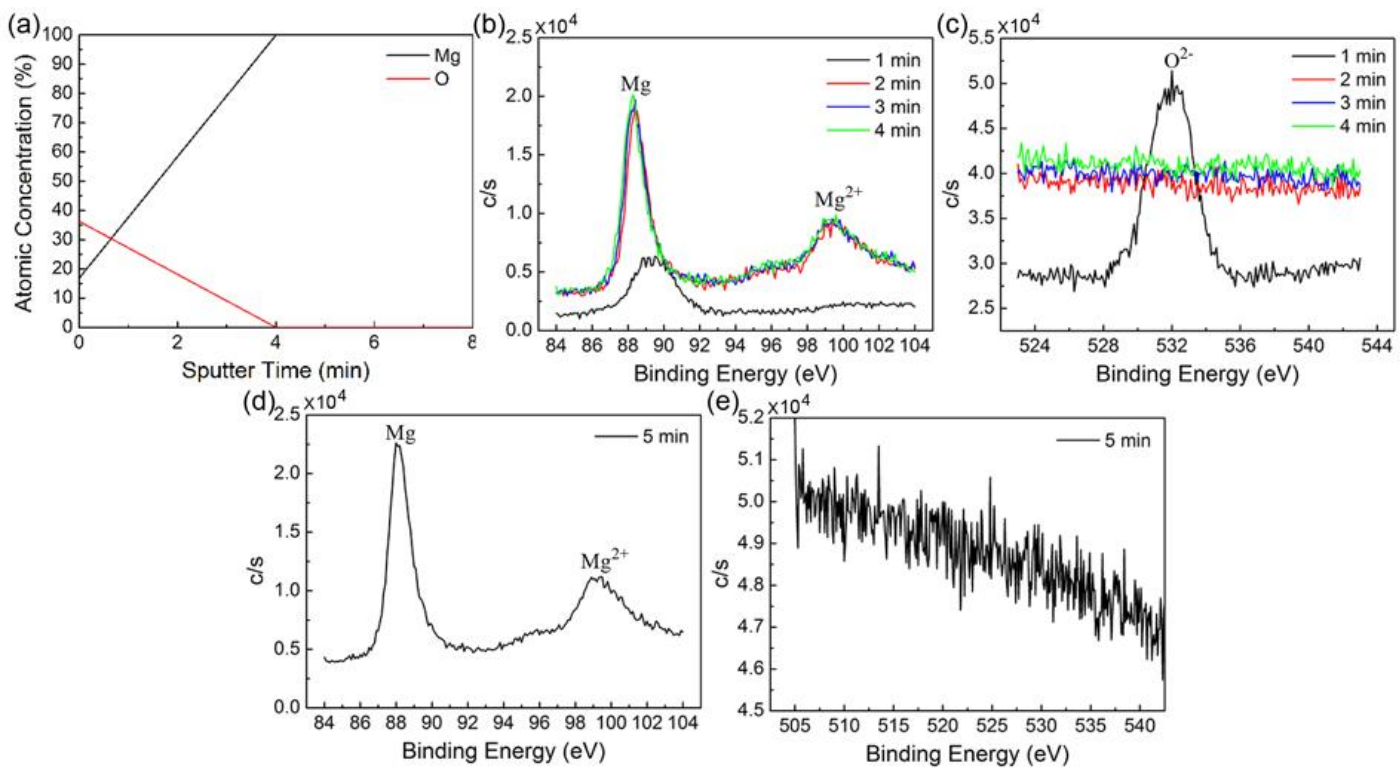

Figure 11. Ion sputtering and XPS results in as-sprayed sample: (a) atomic concentration of $\mathrm{Mg}$ and $\mathrm{O}$ vs sputter time; narrow band spectrum of (b) $\mathrm{Mg} 2 \mathrm{~s}$ and (c) $\mathrm{O}$ 1s at sputter time of $1 \mathrm{~min}, 2 \mathrm{~min}, 3 \mathrm{~min}$ and $4 \mathrm{~min}$; narrow band spectrum of (d) $\mathrm{Mg} 2 \mathrm{~s}$ and (e) $\mathrm{O} 1 \mathrm{~s}$ at sputtering for 5 minutes.

\section{Discussion}

\subsection{Microstructure-property relationship}

To compare with the tensile results of AZ80 alloys in this study, a large number of previous studies [26, 27, 39, 40, 50-67] on tensile properties at room temperature for $\mathrm{AZ}$ series $\mathrm{Mg}$ alloys processed by ECAP were summarized in Figure 12. Clearly, the YS and EF follows an often-observed trend of strength-ductility trade-off: i.e., high strength accompanied with low ductility, and vice versa. Specifically, with the 
increasing solute concentration from AZ31 to AZ91, the YS increases and the EF decreases. For instance, the AZ31 alloys provide the best plastic deformation ability with an EF of $60 \%$ and a YS of $170 \mathrm{MPa}$ [41], while the AZ91 alloys possess a high YS of $\sim 300 \mathrm{MPa}$ and an EF of $\sim 9 \%$ [48]. Moreover, AZ31 alloy could have a high YS of $372 \mathrm{MPa}$ and a low EF of $1 \%$ by ECAP grain refinement. The present tensile results obtained for the as-sprayed-ECAP and as-cast-ECAP AZ80 samples also follow the same trends in the literature data. In addition, the as-sprayed-ECAP shows the best properties among reported AZ80 alloys.

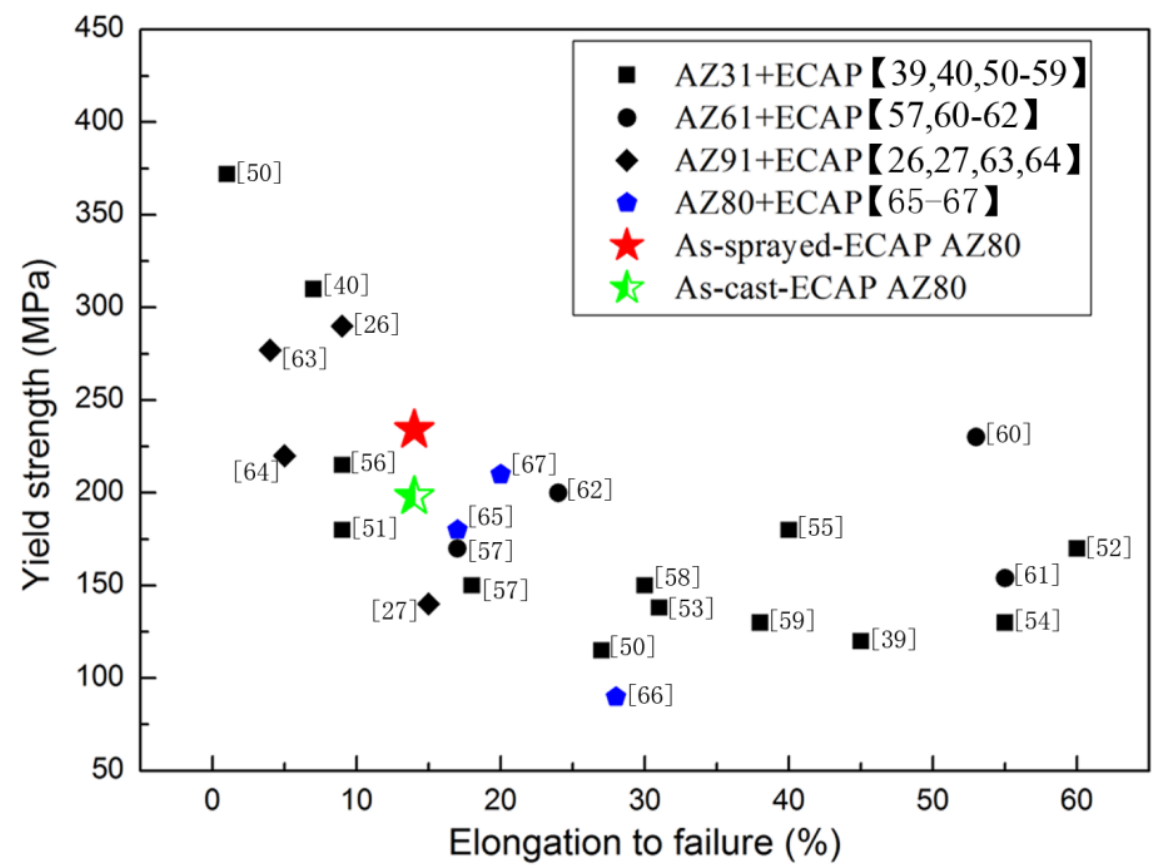

Figure 12. The yield strength versus ductility at room temperature for $\mathrm{AZ}$ series $\mathrm{Mg}$ alloys (AZ31, AZ61, AZ91and AZ80 alloys) processed by ECAP.

The observed simultaneous improvement of strength and ductility of the $\mathrm{Mg}$ alloys by ECAP processing can be primarily attributed to their unique structure, which is similar to the bi-modal "harmonic structure" formed by consolidation of severe plastically deformed powders [45]. Such a microstructure is characterized by soft CG domains embedded in continuous strong UFG network matrix. Simultaneous increase in both strength and ductility is typically observed for such a structure. It is also to some extent similar to the heterogeneous structure reported in $\mathrm{Ti}$, which has been 
reported to have the strength of the UFG Ti and ductility of CG Ti [68].This type of structure is found to produce high back stress and back stress hardening, which improves both the yield strength and ductility. The back stress evolution during a tensile test can be measured by the approach of unloading-reloading at varying tensile strains [69].The back stress in the present Mg alloy samples will be further studied.

The dispersed distribution of $\beta-\mathrm{Mg}_{17} \mathrm{Al}_{12}$ particles in the UFG deformation layer should also have played an important role in the mechanical behavior. It is known that strengthening and toughening can be obtained through dispersed hard particles to interact with dislocations or grain boundaries. For example, tensile properties have been reported improved by adding $\mathrm{La}_{2} \mathrm{O}_{3}$ particles in molybdenum alloys [70]. The $\mathrm{Mg}_{17} \mathrm{Al}_{12}$ particles in $\mathrm{AZ80}$ alloy may have the same effect. Though $\mathrm{Mg}_{17} \mathrm{Al}_{12}$ particles were normally reported to precipitate along the original grain boundaries [29], their formation mechanism within deformation layers is still not clear. Zhao et al. proposed that ECAP process could accelerate precipitation in UFG $7075 \mathrm{Al}$ alloy [71]. Thus, it is speculated that the formation of so many $\mathrm{Mg}_{17} \mathrm{Al}_{12}$ particles may come from two ways: new precipitation or the fracture and redistribution of original large network-shaped $\beta$-phase.

\subsection{Strengthening factors}

The relationship between microstructure and properties has been discussed in Section 4.1. In order to further shed light on the relationship, the responding values of ( I) grain refinement, ( II) solid solution, (III) second phase, and (IV) dislocations are estimated in this section. It should be noted that these are only qualitative estimations, and the interaction between these factors are highly possible but is not considered.

Generally, grain refinement strengthening can be described by the Hall-Petch equation

$$
\sigma_{\mathrm{hp}}=\sigma_{0}+\mathrm{kd}^{1 / 2}
$$

For the ECAP-processed AZ80 alloys with bi-modal structure here, based on the mixture rule, it can be rewrote to

$$
\sigma_{\mathrm{hp}}=\sigma_{0}+\mathrm{xk} / \sqrt{\mathrm{d}_{\mathrm{CG}}}+(1-\mathrm{x}) \mathrm{k} /{ }_{21}^{\sqrt{\mathrm{d}_{\mathrm{UFG}}}}
$$


where $\sigma_{0}$ of pure $\mathrm{Mg}$ is about $11 \mathrm{MPa}$ [72]; $\mathrm{k}$ is a constant, which is $0.28 \mathrm{MNm}^{-3 / 2}$ for $\mathrm{Mg}$ [73]; $\mathrm{d}$ in equation (1) is $40 \mu \mathrm{m}$ and $60 \mu \mathrm{m}$ for as-sprayed and as-cast samples; $\mathrm{d}_{\mathrm{CG}}$ and $\mathrm{d}_{\mathrm{UFG}}$ in equation (2) are the average grain size of $\mathrm{CG}$ and UFG $\alpha-\mathrm{Mg}$ phase, using the values of $25 \mu \mathrm{m}$ and $45 \mu \mathrm{m}$ for $\mathrm{d}_{\mathrm{CG}}, 0.6 \mu \mathrm{m}$ and $0.8 \mu \mathrm{m}$ for $\mathrm{d}_{\mathrm{UFG}}$ in the as-sprayed-ECAP and as-cast-ECAP samples, respectively; $\mathrm{x}$ represents for the area fraction of UG $\alpha-\mathrm{Mg}$ phase, which can be expressed by $\mathrm{d}_{\mathrm{CG}}{ }^{2} / 4 \mathrm{r}_{\mathrm{UFG}}\left(\mathrm{d}_{\mathrm{CG}}+\mathrm{r}_{\mathrm{UFG}}\right), \mathrm{r}_{\mathrm{UFG}}$ is the average thickness of deformation layer and 20 $\mu \mathrm{m}$ and $10 \mu \mathrm{m}$ for the as-sprayed-ECAP and as-cast-ECAP samples, respectively, according to the calculation from SEM micrographs. Therefore, grain refinement strengthening contributions are about 55, 47, 87 and $76 \mathrm{MPa}$ for the as-sprayed, as-cast, as-sprayed-ECAP and as-cast-ECAP samples, respectively.

Solid solution strengthening occurs as a consequence of the interactions between moving dislocations and the strain fields associated with misfit solute atoms, and can be expressed by [74]

$$
\sigma_{\mathrm{ss}}=\sigma_{0}+\frac{3.1 \varepsilon \mathrm{GC}^{1 / 2}}{700}
$$

where $\varepsilon$ is an experimental constant, which is 0.22 for $\mathrm{Mg}$ - $\mathrm{Al}$ series alloys [72]; $\mathrm{G}$ is the shear modulus, which is $1.66 \times 10^{4} \mathrm{MPa}$ for $\mathrm{Mg}$ [73]; $\mathrm{C}$ is the solute concentration in atomic percentage. For as-sprayed and as-cast samples, it is speculated that $\mathrm{Al}$ and $\mathrm{Zn}$ solutes were totally dissolved into $\mathrm{Mg}$ matrix and the surplus of $\mathrm{Al}$ and $\mathrm{Zn}$ addition is 7.6 at.\%. In the ECAP-processed samples, the solid solution strengthening contribution decreases due to the fact that the matrix is depleted of solute as the $\beta-\mathrm{Mg}_{17} \mathrm{Al}_{12}$ precipitation process proceeds. According to $\mathrm{Mg}-\mathrm{Al}$ and $\mathrm{Mg}-\mathrm{Zn}$ binary phase diagram at temperature of $200{ }^{\circ} \mathrm{C}$ (the final ECAP processing temperature), the surplus of $\mathrm{Al}$ and $\mathrm{Zn}$ addition is 4.1 at.\%. Finally, for as-sprayed (as-cast) and as-sprayed-ECAP (as-cast-ECAP), increase of YS resulted from solid solution strengthening is $56 \mathrm{MPa}$ and $43 \mathrm{MPa}$.

The second-phase particle strengthening can be estimated by the Orowan process which describes the interactions between the second particles and by [75] 


$$
\sigma_{\text {Orowan }}=\frac{0.4 \mathrm{MGb}}{\pi(1-v)^{1 / 2}} \frac{\ln (\overline{\mathrm{d}} / \mathrm{b})}{\lambda}
$$

where $\mathrm{M}$ is the Taylor factor, which is 6.5 for $\mathrm{Mg}$ [73]; $\mathrm{b}$ is the Burgers vector, which is $3.21 \times 10^{-10} \mathrm{~m}$ for $\mathrm{Mg}$ [73] and $v$ is the Poisson's ratio (0.35) [73]. $\overline{\mathrm{d}}$ equals $\sqrt{2 / 3} \mathrm{~d}_{\mathrm{UFG}}$ and $\lambda$ can be rewrote as $\overline{\mathrm{d}}(\sqrt{\pi / 4 \mathrm{f}}-1)$. f represents the volume fraction of the second-phase particles, which is 0.16 and 0.13 for the as-sprayed-ECAP and as-cast-ECAP samples. The YS increase of 88 and $70 \mathrm{MPa}$ for the as-sprayed-ECAP and as-cast-ECAP samples, respectively, are attributed to the second-phase particle strengthening.

Dislocation strengthening can be calculated on the basis of the Taylor formula [76]

$$
\tau=\operatorname{CGb} \rho^{1 / 2}
$$

where $\rho$ is the density of dislocations, $\mathrm{C}$ is a constant assumed to be 0.3 by Ashby [77]. Using the relationship of threefold between the normal stress $\sigma$ and shear stress $\tau$, the YS has increased by $21 \mathrm{MPa}$ and $16 \mathrm{MPa}$, respectively, due to the dislocation strengthening.

Table 5. Relative contributions of different strengthening mechanisms to the yield strength (YS) of the AZ80 alloy (unit: MPa). The data in brackets show percentage of the contributions.

\begin{tabular}{ccccccc}
\hline & $\begin{array}{c}\text { Fine grain } \\
\text { strengthening }\end{array}$ & $\begin{array}{c}\text { Solid solution } \\
\text { strengthening }\end{array}$ & $\begin{array}{c}\text { Second phase } \\
\text { strengthening }\end{array}$ & $\begin{array}{c}\text { Dislocation } \\
\text { strengthening }\end{array}$ & $\begin{array}{c}\text { Theoretical } \\
\text { YS }\end{array}$ & $\begin{array}{c}\text { Tensile } \\
\text { YS }\end{array}$ \\
\hline as-sprayed & 55 & 56 & 0 & 0 & 111 & 140 \\
as-cast & 47 & 56 & 0 & 0 & 103 & 100 \\
as-sprayed-ECAP & 87 & 43 & 88 & 21 & 239 & 235 \\
as-cast-ECAP & 76 & 43 & 70 & 16 & 205 & 200 \\
$\triangle_{\text {as-sprayed-ECAP- as-sprayed }}$ & $32(+21 \%)$ & $-13(-8 \%)$ & $88(+57 \%)$ & $21(+14 \%)$ & & \\
$\triangle_{\text {as-cast-ECAP - as-cast }}$ & $29(+23 \%)$ & $-13(-10 \%)$ & $70(+55 \%)$ & $16(+13 \%)$ & & \\
\hline
\end{tabular}

Table 5 compares different strengthening contributions: after ECAP processing, the second-phase particle strengthening contributes about $55 \%$ of the overall strength, which can be ascribed to the advantageous distributions and morphologies of 
$\beta-\mathrm{Mg}_{17} \mathrm{Al}_{12}$ particles. The grain refinement and dislocation strengthening contributions are about $20 \%$ and $15 \%$, respectively. However, because of depletion of Al to form $\mathrm{Mg}_{17} \mathrm{Al}_{12}$ particles, the contribution of solid solution strengthening decreases by about $10 \%$.

\section{Conclusions}

In this study, we synthesized CG AZ80 Mg alloys by casting and spray forming, followed by extrusion and ECAP at different temperatures. The sample prepared by spray forming and ECAP process has a yield strength of $235 \mathrm{MPa}$ and a tensile elongation to failure of $14 \%$, which are much larger than their conventional counterparts (with yield strength-elongation to failure combinations of $140 \mathrm{MPa}-5 \%$ ). Microstructure investigations revealed that the excellent strength and ductility combination is attributed to a unique bi-modal structure: coarse $\mathrm{Mg}$ grains were separated and surrounded by deformation networks consisting of ultrafine grained $\mathrm{Mg}$ and ellipsoidal shaped $\beta-\mathrm{Mg}_{17} \mathrm{Al}_{12}$ particles. Such a unique microstructure is believed to produce high back stress and back stress hardening to enhance both the strength and ductility. The $\mathrm{Mg}_{17} \mathrm{Al}_{12}$ second-phase strengthening made greatest contribution to the yield strength. This work indicates that the combination ECAP processing with spray forming can dramatically improve the mechanical properties of $\mathrm{AZ} 80 \mathrm{Mg}$ alloys.

\section{Acknowledgements}

The authors gratefully acknowledge financial support of Program for New Century Excellent Talents in University from Chinese Ministry of Education, National Natural Science Foundation of China (51225102 and 2012CB932203). The $8^{\text {th }}$ "Liu da Ren cai Gao feng B932203) from Jiangsu Province, China, and the Jiangsu Key Laboratory of Advanced Nanomaterials and Technologies. SEM, TEM and X-ray were performed in the Materials Characterization Facility of the Nanjing University of Science and Technology. R.K. would like to acknowledge the support provided by the Russian Ministry of Education and Science within the basic part of the program for universities supported by the Russian Ministry for Education and Science (RZV 
through the Grant No 14.B25.31.0017). E.J.L. acknowledge the support from National Science Foundation of the United States (CMMI-1631873 NSF-CMMI-1437327). YTZ acknowledge the support of the China 1000Plan program and the U.S. Army Research Office (W911NF-12-1-0009).

\section{References}

[1] A.A. Luo, Journal of Magnesium and Alloys, 1 (2013) 2-22.

[2] R.Z. Valiev, R.K. Islamgaliev, I.V. Alexandrov, Progress in materials science, 45 (2000) 103-189.

[3] M. Lalpoor, J. Dzwonczyk, N. Hort, S. Offerman, Journal of Alloys and Compounds, 557 (2013) 73-76.

[4] J. Chen, Y. Song, D. Shan, E.H. Han, Corrosion Science, 93 (2015) 90-99.

[5] T. Laha, Y. Chen, D. Lahiri, A. Agarwal, Composites Part A: Applied Science and Manufacturing, 40 (2009) 589-594.

[6] J. Mi, P. Grant, Acta Materialia, 56 (2008) 1588-1596.

[7] R.A. Mesquita, C.A. Barbosa, Materials Science and Engineering: A, 383 (2004) $87-95$.

[8] G. Antipas, C. Lekakou, P. Tsakiropoulos, Materials Characterization, 62 (2011) 402-408.

[9] B.Q. Han, E.J. Lavernia, F.A. Mohamed, Metallurgical and Materials Transactions A, 36 (2005) 345-355.

[10] L. Lu, L.G. Hou, J.X. Zhang, H.B. Wang, H. Cui, J.F. Huang, Y.A. Zhang, J.S. Zhang, Journal of Materials Research, (2016) 1-7.

[11] Z. Li, X. Yang, J. Zhang, B. Zheng, Y. Zhou, A. Shan, E.J. Lavernia, Metallurgical and Materials Transactions A,, 45 (2014) 5017-5028.

[12] J. Schreiber, Z. Omcikus, T. Eden, M. Sharma, V. Champagne, S. Patankar, Journal of Alloys and Compounds, 617 (2014) 135-139.

[13] D.Y. Yang, W.Y. Xu, Z. Li, G.Q. Zhang, Z.L. Ning, J.F. Sun, Materials Science Forum, 2013, pp. 564-568.

[14] C. Chen, C.Y. Tsao, Materials Science and Engineering: A, 383 (2004) 21-29. 
[15] X.F. Wang, J.Z. Zhao, J. He, Z.Q. Hu, Transactions of Nonferrous Metals Society of China, 17 (2007) 238-243.

[16] Y.T. Zhu, T.C. Lowe, Materials Science and Engineering: A, 291 (2000) 46-53.

[17] C. Howard, D. Frazer, A. Lupinacci, S. Parker, R. Valiev, C. Shin, B.W. Choi, P. Hosemann, Materials Science and Engineering: A, 649 (2016) 104-113.

[18] Y.H. Zhao, X.Z. Liao, Y.T. Zhu, R.Z. Valiev, Journal of materials research, 20 (2005) 288-291.

[19] A.V. Polyakov, I.P. Semenova, Y. Huang, R.Z. Valiev, T.G. Langdon, Advanced Engineering Materials, 16 (2014) 1038-1043.

[20] V.G. Pushin, R.Z. Valiev, Y.T. Zhu, D.V. Gunderov, N.I. Kourov, T.E. Kuntsevich, A.N. Uksusnikov, L.I. Yurchenko, Materials transactions, 47 (2006) 694.

[21] J. Suh, J. Victoria-Hernández, D. Letzig, R. Golle, W. Volk, Materials Science and Engineering: A, 650 (2016) 523-529.

[22] C. Haase, O. Kremer, W. Hu, T. Ingendahl, R. Lapovok, D.A. Molodov, Acta Materialia, 107 (2016) 239-253.

[23] H. Liu, Z. Sun, G. Wang, X. Sun, J. Li, F. Xue, H. Peng, Y. Zhang, Materials Science and Engineering: A, 654 (2016) 107-112.

[24] X. Yang, H. Miura, T. Sakai, Materials \& Design, 44 (2013) 573-579.

[25] Y. Miyahara, Z. Horita, T.G. Langdon, Materials Science and Engineering: A, 420 (2006) 240-244.

[26] W. Kim, J. Park, W. Kim, Journal of Alloys and Compounds, 460 (2008) 289-293.

[27] A. Yamashita, Z. Horita, T.G. Langdon, Materials Science and Engineering: A, 300 (2001) 142-147.

[28] F. Lu, A. Ma, J. Jiang, D. Yang, Y. Yuan, L. Zhang, Journal of Alloys and Compounds, 601 (2014) 140-145.

[29] X. Yang, H. Miura, T. Sakai, Materials transactions, 46 (2005) 2981-2987.

[30] H. Kitahara, F. Maruno, M. Tsushida, S. Ando, Materials Science and Engineering: A, 590 (2014) 274-280.

[31] P. Wang, F.Y. Han, Y.S. Wang, L. Geng, S.F. Meng, W. Liang, Advanced 
Materials Research, 602 (2013) 602-607.

[32] H. Jafarzadeh, K. Abrinia, A. Babaei, Materials Science and Engineering: A, 596 (2014) 194-199.

[33] H. Wang, K. Zhou, G. Xie, X. Liang, W. Liang, Y. Zhao, Materials Science and Engineering: A, 560 (2013) 787-791.

[34] B. Chen, D.L. Lin, L. Jin, X.Q. Zeng, C. Lu, Materials Science and Engineering: A, 483 (2008) 113-116.

[35] A.S.H. Kabir, J. Su, S. Yue, Metallurgical and Materials Transactions B, (2016) $1-7$.

[36] S.M. Arab, A. Akbarzadeh, Journal of Magnesium and Alloys, 2 (2014) 203-207.

[37] R. Jahadi, M. Sedighi, H. Jahed, Materials Science and Engineering: A, 593 (2014) 178-184.

[38] R.B. Figueiredo, T.G. Langdon, Materials Science and Engineering: A, 501 (2009) 105-114.

[39] T. Mukai, M. Yamanoi, H. Watanabe, K. Higashi, Scripta Materialia, 45 (2001) 89-94.

[40] H. Lin, J. Huang, T. Langdon, Materials Science and Engineering: A, 402 (2005) 250-257.

[41] D. Foley, M. Al-Maharbi, K. Hartwig, I. Karaman, L. Kecskes, S. Mathaudhu, Scripta Materialia, 64 (2011) 193-196.

[42] M. Bleckmann, M. Eichhorst, M. Schuch, W. Kreuzer, V. Hammond, C. Spiller, L. Meyer, N. Herzig, Materials Science and Engineering: A, 660 (2016) 108-117.

[43] P. Molnár, A. Jäger, Philosophical Magazine, 93 (2013) 3612-3626.

[44] S. Biswas, S. Singh Dhinwal, S. Suwas, Acta Materialia, 58 (2010) 3247-3261.

[45] Z. Zhang, S.K. Vajpai, D. Orlov, K. Ameyama, Materials Science and Engineering: A, 598 (2014) 106-113.

[46] S. Celotto, Acta Materialia, 48 (2000) 1775-1787.

[47] A. Dhar, R. Anandani, A. Srivastava, Materials Science and Technology, 27 (2011) 1275-1280.

[48] A. Vinogradov, D. Orlov, A. Danyuk, Y. Estrin, Acta Materialia, 61 (2013) 
2044-2056.

[49] Z. Li, A. Luo, Q. Wang, L. Peng, P. Fu, G. Wu, Materials Science and Engineering: A, 564 (2013) 450-460.

[50] S. Ding, W. Lee, C. Chang, L. Chang, P. Kao, Scripta Materialia, 59 (2008) 1006-1009.

[51] H.K. Kim, Y.-I. Lee, C.-S. Chung, Scripta Materialia, 52 (2005) 473-477.

[52] W.J. Kim, H.T. Jeong, Materials transactions, 46 (2005) 251-258.

[53] Z. Zúberová, L. Kunz, T. Lamark, Y. Estrin, M. Janeček, Metallurgical and Materials Transactions A, 38 (2007) 1934-1940.

[54] H. Somekawa, T. Mukai, Scripta Materialia, 54 (2006) 633-638.

[55] C. Su, B. Chua, L. Lu, M. Lai, Materials Science and Engineering: A, 402 (2005) 163-169.

[56] H.K. Kim, Materials Science and Engineering: A, 515 (2009) 66-70.

[57] S.Y. Chang, S.W. Lee, K.M. Kang, S. Kamado, Y. Kojima, Materials transactions, 45 (2004) 488-492.

[58] W. Kim, Y. Sa, Scripta Materialia, 54 (2006) 1391-1395.

[59] S. Agnew, J. Horton, T. Lillo, D. Brown, Scripta Materialia, 50 (2004) 377-381.

[60] W. Kim, C. An, Y. Kim, S. Hong, Scripta Materialia, 47 (2002) 39-44.

[61] W. Kim, S. Hong, Y. Kim, S. Min, H. Jeong, J. Lee, Acta Materialia, 51 (2003) 3293-3307.

[62] J. Jiang, Y. Wang, J. Qu, Materials Science and Engineering: A, 560 (2013) 473-480.

[63] Y. Chino, M. Mabuchi, Advanced Engineering Materials, 3 (2001) 981-983.

[64] K. Máthis, J. Gubicza, N. Nam, Journal of Alloys and Compounds, 394 (2005) 194-199.

[65] T.S. Pereira, C.W. Chung, R. Ding, Y.L. Chiu, IOP Conference Series: Materials Science and Engineering, 2009, pp. 012022.

[66] P. Mehrotra, T. Lillo, S. Agnew, Scripta Materialia, 55 (2006) 855-858.

[67] B. Shi, R. Chen, W. Ke, Materials Science and Engineering: A, 546 (2012) 323-327. 
[68] X.L. Wu, M.X. Yang, F.P. Yuan, G.L. Wu, Y.J. Wei, X.X. Huang, Y.T. Zhu, Proceedings of the National Academy of Sciences, 112 (2015) 14501-14505.

[69] M.X. Yang, Y. Pan, F.P. Yuan, Y.T. Zhu, X.L. Wu, Materials Research Letters, (2016) 1-7.

[70] G. Liu, G. Zhang, F. Jiang, X. Ding, Y. Sun, J. Sun, E. Ma, Nature materials, 12 (2013) 344-350.

[71] Y.H. Zhao, X.Z. Liao, Z. Jin, R.Z. Valiev, Y.T. Zhu, Acta Materialia, 52 (2004) 4589-4599.

[72] C. Caceres, D. Rovera, Journal of Light Metals, 1 (2001) 151-156.

[73] R. Armstrong, I. Codd, R. Douthwaite, N. Petch, Philosophical Magazine, 7 (1962) 45-58.

[74] R.W. Hertzberg, R.P. Vinci, J.L. Hertzberg, Deformation and fracture mechanics of engineering materials, Wiley New York, 1996.

[75] L. Brown, R. Ham, A. Kelly, R. Nicholson, Applied Science, London, (1971) 9.

[76] M.F. Ashby, Philosophical Magazine, 21(1970)399

[77] N. Fleck, G. Muller, M. Ashby, J. Hutchinson, Acta Metallurgica Materialia 42 (1994) 475-487. 